This is the final peer-reviewed accepted manuscript of:

Marco Calizzi, Domizia Chericoni, Lars H. Jepsen, Torben R. Jensen, Luca Pasquini, $\mathrm{Mg}$-Ti nanoparticles with superior kinetics for hydrogen storage, International Journal of Hydrogen energy, 2016, volume 41, issue 32, pages 14447-14454.

The final published version is available online at: https://doi.org/10.1016/j.ijhydene.2016.03.071

Rights / License:

The terms and conditions for the reuse of this version of the manuscript are specified in the publishing policy. For all terms of use and more information see the publisher's website. 


\title{
Mg-Ti nanoparticles with superior kinetics for hydrogen storage
}

Marco Calizzi ${ }^{a, *}$, Domizia Chericoni ${ }^{a}$, Lars H. Jepsen ${ }^{b}$, Torben R. Jensen ${ }^{b}$ and Luca Pasquinia

a. Department of Physics and Astronomy - Alma Mater Studiorum, University of Bologna, viale BertiPichat 6/2, 40127 Bologna, Italy

b. Center for Materials Crystallography (CMC), Interdisciplinary Nanoscience Center (iNANO), Department of Chemistry, Aarhus University, Langelandsgade 140, DK-8000 Aarhus C, Denmark

*. Corresponding author: e-mail marco.calizzi@unibo.it, tel. +39 0512095133

\begin{abstract}
Mg nanoparticles (NPs) with addition of Ti catalysts were synthesised by inert gas condensation and in situ hydrogenation at $150^{\circ} \mathrm{C}$. The NPs size and composition were systematically investigated by scanning electron microscopy, energy dispersive $x$-ray spectroscopy and powder x-ray diffraction (PXD), while time resolved in situ synchrotron radiation-PXD was used to monitor the mechanism for hydrogen uptake and release at $280^{\circ} \mathrm{C}$. The $\mathrm{Mg}-\mathrm{Ti}$ NPs reveal activation energies of $68 \mathrm{~kJ} \mathrm{~mol}^{-1}$ for absorption and $78 \mathrm{~kJ} \mathrm{~mol}^{-1}$ for desorption by isothermal kinetics analysis, similar to the lowest values reported in the literature for $\mathrm{MgH}_{2}$ using $\mathrm{Nb}_{2} \mathrm{O}_{5}$ as a catalyst. Hence, hydrogen desorption ( $p_{\text {des }}=8 \mathrm{mbar}$ ) and absorption ( $p_{\text {abs }}=260 \mathrm{mbar}$ ) is achieved at $200{ }^{\circ} \mathrm{C}$ in $\sim 2000 \mathrm{~s}$, while keeping $5.3 \mathrm{wt} \%$ storage capacity. Thermodynamic data extracted from Van 't Hoff plots reveal unchanged values compared to bulk

$\mathrm{MgH}_{2}$. Therefore, the improved hydrogen storage performances are assigned to the enhanced kinetics only.
\end{abstract}

\section{Introduction}

To use hydrogen $(H)$ as an energy carrier, a still missing adequate storage system is needed. The idea of using metal hydrides to store $\mathrm{H}$ is more than 30 years old, but the research field is still very active, and a range of different properties of metal hydrides have recently been discovered [1,2]. Magnesium hydride $\left(\mathrm{MgH}_{2}\right)$ is an attractive material because of its high $\mathrm{H}$ storage capacity $(7.66 \mathrm{wt} \%)$ and low cost, but it is thermodynamically too stable and the $\mathrm{H}$-sorption kinetics are poor, leading to operation temperatures above $300{ }^{\circ} \mathrm{C}$, unpractical for applications. Thermodynamic destabilisation of $\mathrm{MgH}_{2}$ and/or kinetics enhancement were observed synthesising Mg-based alloys [3], nanostructuring the material [4] or by addition of catalysts $[5,6]$. A nanostructure with high surface to volume ratio and short diffusion paths improve the kinetic properties. Calculations show that nanostructure refinement could also thermodynamically destabilise $\mathrm{MgH}_{2}$ through interface energy effects [7] or elastic constraints [8,9]. Titanium (Ti) is an efficient catalyst, and $\mathrm{Mg}$ with addition of $\mathrm{Ti}$ or $\mathrm{TiH}_{2}$ showed kinetics among the fastest for Mg-based materials [10,11]. Despite the immiscibility of $\mathrm{Ti}$ and $\mathrm{Mg}$ [12], the $\mathrm{Mg}-\mathrm{Ti}$ and the $\mathrm{Mg}-\mathrm{Ti}-\mathrm{H}$ systems have been investigated looking for metastable compounds with different thermodynamic properties [13,14,15]. To prepare nanostructured Mg-Ti composites and compounds the most used techniques are ball milling [13-16] and magnetron sputtering $[7,17,18]$.

In this work, we present the excellent $\mathrm{H}$-sorption properties of Mg-based, Mg-Ti nanoparticles synthesised via inert gas condensation. The thermodynamics, kinetics and reaction mechanisms of this system were analysed from $300{ }^{\circ} \mathrm{C}$ down to $200^{\circ} \mathrm{C}$. 

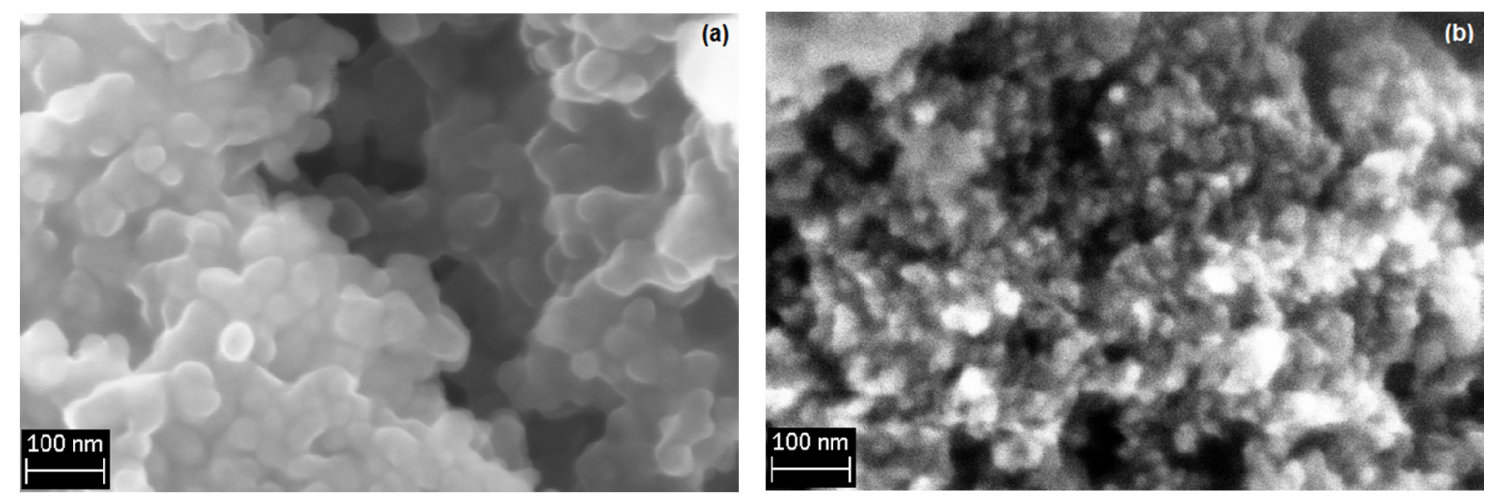

Figure 1: SEM images showing the morphology of as-prepared NPs in sample A (a) and B (b).

\section{Experimental methods}

Mg-Ti nanoparticles (NPs) were synthesised via Inert Gas Condensation (IGC). The synthesis chamber was evacuated to $10^{-7}$ mbar before the evaporation, then Mg ingots (Alfa Aesar, purity 99.9\%) and Ti powder (Alfa Aesar, purity 99.9\%, 150 mesh) were evaporated simultaneously in two Joule-heated tungsten boats under a He flow (purity 99.9999\%). The He pressure in the chamber was kept at 2.7 mbar while a mass flow controller set the He flow rate to $7.0 \mathrm{std} \mathrm{cm}^{3} \mathrm{~min}^{-1}$. In this set-up, the He flow crosses the Mg vapour source first, then the hotter $\mathrm{Ti}$ source and finally hits a liquid $\mathrm{N}_{2}$-cooled rotating cylinder where the nanoparticles (NPs) are collected. After the evaporation, NPs are scraped from the cylinder and transferred under high vacuum to the sample-extraction chamber, where they are heated to $150{ }^{\circ} \mathrm{C}$ and exposed to $\mathrm{H}_{2}$ for $\sim 3600 \mathrm{~s}$ before being extracted under Ar atmosphere. The $\mathrm{H}_{2}$ pressure was selected to $133 \mathrm{mbar}$, in order to allow for both $\mathrm{Mg}$ and $\mathrm{Ti}$ hydrogenation at $150^{\circ} \mathrm{C}$. Two samples, named sample $\mathrm{A}$ and $\mathrm{B}$, were prepared with different Ti contents changing the power applied to the boat containing $\mathrm{Ti}$. The amount of material obtained in one batch ranges between $15 \mathrm{mg}$ and $55 \mathrm{mg}$.

Morphological and compositional characterisation was carried out with a Leica Cambridge Stereoscan 360 scanning electron microscope (SEM) equipped with an Oxford Instruments X-ray detector for energy dispersive X-ray spectroscopy (EDX) and with a Leo Zeiss 1530 Gemini field emission (FE)SEM. Laboratory powder X-ray diffraction (PXD) patterns were collected with a PANalytical X'celerator diffractometer using Cu- $K_{\alpha}$ radiation (1.5406 $\AA$ ) and analysed using MAUD Rietveld refinement software [19] on as-prepared and cycled (after absorption) samples.

A homemade Sievert's type apparatus was employed to measure isothermal kinetics on both samples and pressure-composition isotherms $(\mathrm{PCl})$ on sample A between $200 \quad{ }^{\circ} \mathrm{C}$ and $300 \quad{ }^{\circ} \mathrm{C}$. The time evolution of the compounds during $\mathrm{H}$ absorption and desorption was studied by the in situ synchrotron radiation (SR)-PXD set-up $[20,21]$ implemented at the beamline 1711 of MAX II synchrotron in the research laboratory MAX-lab, Lund, Sweden. Sample A was kept at $280^{\circ} \mathrm{C}$ and alternately exposed to vacuum ( 0.08 bar) and $\mathrm{H}_{2}$ pressure ( $>5$ bar) in order to complete five cycles while recording PXD pattern every 34 s. The X-ray wavelength used for this experiment was $0.9938 \AA$. Samples loaded into the Sievert's apparatus or into the SR-PXD set-up were transferred from the synthesis chamber under Ar atmosphere.

\section{Results}

Initial and in situ characterisation The FESEM pictures in Fig. 1 show the typical morphology of the asprepared samples. The individual NPs can be resolved within the large agglomerates, which constitute the nanopowder. The NPs size is in the $10-20 \mathrm{~nm}$ range, in agreement with reports on similar samples [22]. The $\mathrm{Ti}$ atomic fraction measured by EDX, considering only $\mathrm{Mg}$ and $\mathrm{Ti}$ elements, was $\sim 6$ at\% for 

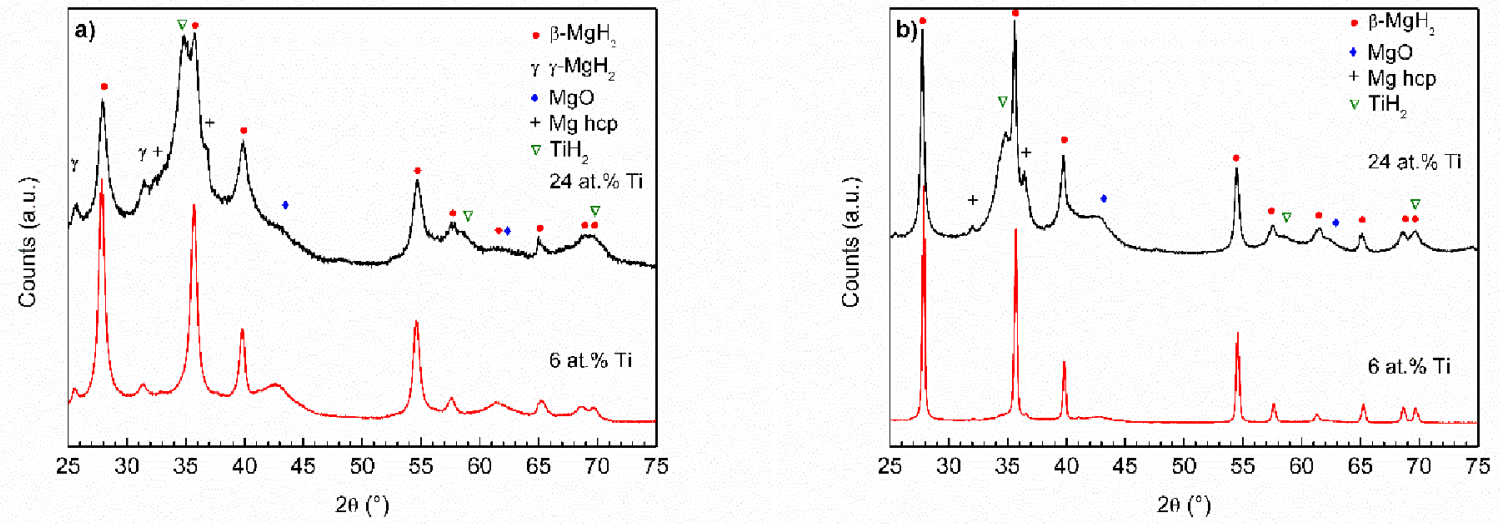

Figure 2: PXD patterns $(\lambda=1.5406 \AA)$ of samples A and B (a) in the as-prepared state and (b) after cycling in the Sievert's apparatus.

sample A and $\sim 24$ at\% for sample B. The different Ti contents do not induce evident changes in NPs shape or level of aggregation, but have an effect on the average NP size. NPs in sample B (Fig. 1b) appear smaller than those of sample A (Fig. 1a), with a lower Ti content. This is also in agreement with the measured mean crystallite size as it will be discussed quantitatively in the following $\mathrm{X}$-ray diffraction study.

PXD patterns of the as-prepared samples are presented in Fig. 2a. The in situ H-treatment led to almost complete hydride formation, with little or no traces of hcp $\mathrm{Mg}$. In both samples, $\mathrm{MgH}_{2}$ appears mainly as the rutile $\beta$-phase with minor amounts of the less stable, orthorhombic $\gamma$-phase. In sample $B$ with $\sim 24$ at\% Ti content, the Bragg reflections of $\mathrm{TiH}_{2}$ are clearly visible. Fine crystallite sizes of about $5 \mathrm{~nm}$ are revealed by the Scherrer equation using profile parameters extracted by Rietveld refinements. $\mathrm{TiH}_{2}$ is likely present in sample $A$ too, but the broad and overlapped diffraction peaks are hardly detected at $\sim 6$ at\% Ti. A thin MgO layer is formed around the NPs since laboratory PXD was carried out in air. Table 1 reports the phase abundances and mean crystallite sizes obtained by the Rietveld analysis.

Sample A was studied with the in situ SR-PXD technique during five desorption-absorption cycles at 280 ${ }^{\circ} \mathrm{C}$. All the SR-PXD patterns taken during the five cycles are plotted in Fig. 3. $\mathrm{Mg}$ and $\mathrm{MgH}_{2}$ peaks appear and disappear alternately as the sample is exposed to $\mathrm{H}_{2}$ pressure or vacuum. To better appreciate the time evolution of the two phases, the intensities of the non-overlapped reflections, i.e. $\mathrm{Mg}$ (100) and $\mathrm{MgH}_{2}$ (110), are normalised between 0 and 1 and plotted as a function of time in Fig. 4. The dashed horizontal line drawn at half intensity highlights the symmetrical evolution of the two phases.

Table 1: weight fraction and mean crystallite size of the phases detected by PXD in the as-prepared samples B and C.

\begin{tabular}{c|cc|cc} 
& \multicolumn{2}{|c|}{ Sample A } & \multicolumn{2}{c}{ Sample B } \\
& $\begin{array}{c}\text { Abundance } \\
\text { (wt.\%) }\end{array}$ & $\begin{array}{c}\text { Cryst. size } \\
\text { (nm) }\end{array}$ & $\begin{array}{c}\text { Abundance } \\
\text { (wt.\%) }\end{array}$ & $\begin{array}{c}\text { Cryst. size } \\
\text { (nm) }\end{array}$ \\
\hline $\mathbf{\beta}_{\mathbf{M g H}} \mathbf{M g H}_{\mathbf{2}}$ & $62 \pm 2$ & $19.4 \pm 1.4$ & $31.0 \pm 0.5$ & $11.3 \pm 0.1$ \\
$\boldsymbol{\gamma}-\mathbf{M g H}_{\mathbf{2}}$ & $5.5 \pm 0.5$ & $15.5 \pm 1.5$ & $16.3 \pm 0.3$ & $9 \pm 3$ \\
$\mathbf{M g O}$ & $32.5 \pm 1.6$ & $3.9 \pm 0.2$ & $10.1 \pm 0.5$ & $5.3 \pm 0.4$ \\
$\mathrm{TiH}_{\mathbf{2}}$ & - & - & $40.7 \pm 0.5$ & $5.0 \pm 0.4$ \\
$\mathbf{M g}$ & - & - & $1.9 \pm 0.1$ & -
\end{tabular}




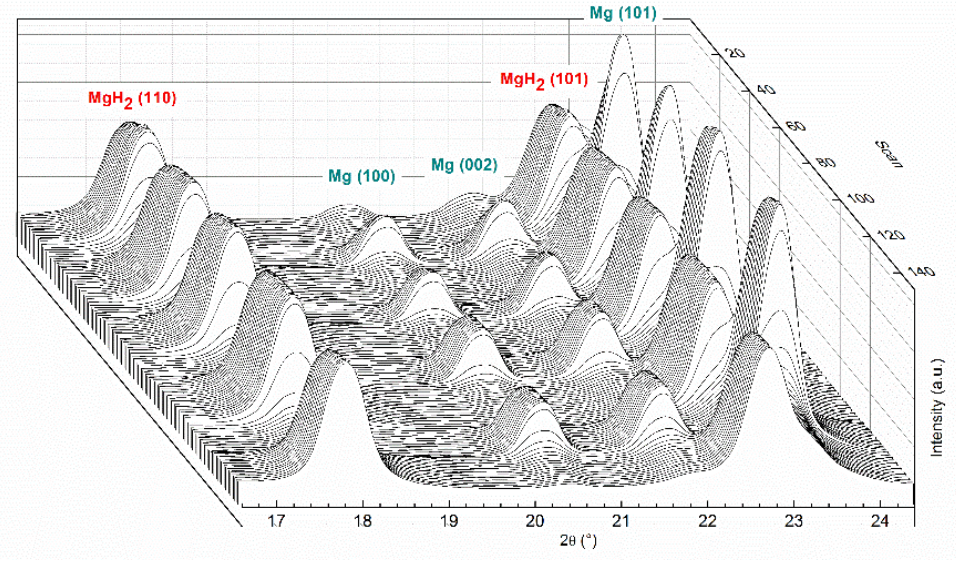

Figure 3: in situ SR-PXD patterns of sample A while being cycled at $280^{\circ} \mathrm{C}$. A diffraction pattern is acquired every $34 \mathrm{~s}$.

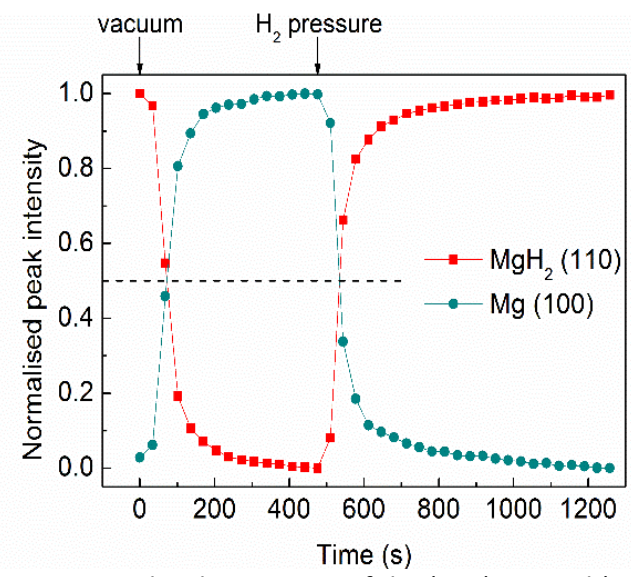

Figure 4: Normalised intensities of the (100) $\mathrm{Mg}$ and (110) $\mathrm{MgH}_{2}$ reflections of Fig. 3 during one cycle. The lines are a guide to the eye.

Thermodynamics and kinetics of $\mathbf{H}$-sorption The thermodynamic properties of the $\mathrm{Mg}-\mathrm{Ti}-\mathrm{H}$ system were investigated by $\mathrm{PCls}$ at $200{ }^{\circ} \mathrm{C}, 220^{\circ} \mathrm{C}$ and $250{ }^{\circ} \mathrm{C}$, in this order. The absorption branches are displayed in Fig. $5 a$, while Fig. $5 b$ shows the first desorption step at each temperature reaching the equilibrium. The horizontal lines in Fig. 5 highlight the small hysteresis between the absorption plateaus and the desorption equilibrium pressures. The pressure-temperature equilibrium points (plotted in the Van ' $t$ Hoff plot in Fig. 6) were used to calculate the enthalpies $(\Delta H)$ and entropies $(\Delta S)$ of formation for the absorption and the desorption case independently, as reported in Table 2 . The H-capacity measured from the PCls in Fig. 5 is $4.1 \mathrm{wt} . \%$ at $200^{\circ} \mathrm{C}$ and $220^{\circ} \mathrm{C}$ and reaches a maximum of $5.3 \mathrm{wt} . \%$ at $250{ }^{\circ} \mathrm{C}$.

Table 2: $\Delta \mathrm{H}$ and $\Delta \mathrm{S}$ for absorption and desorption of sample $\mathrm{A}$, calculated from the Van 't Hoff plot in Fig. 6 . The values of $\Delta \mathrm{H}$ and $\Delta \mathrm{S}$ reported for bulk $\mathrm{MgH}_{2}$ from the literature are reported for comparison.

\begin{tabular}{|c|c|c|}
\hline & $\Delta \mathrm{H}\left(\mathrm{kJ} \mathrm{mol} \mathrm{H}^{-1}\right)$ & $\Delta \mathrm{S}\left(\mathrm{J} \mathrm{K}^{-1} \mathrm{~mol}_{\mathrm{H} 2}{ }^{-1}\right)$ \\
\hline Absorption & $-78.8 \pm 1.1$ & $-142 \pm 2$ \\
\hline Desorption & $-74.1 \pm 0.7$ & $-130.6 \pm 1.4$ \\
\hline 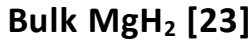 & -74.4 & -135 \\
\hline Bulk $\mathrm{MgH}_{2}[24]$ & -78.5 & -140 \\
\hline
\end{tabular}

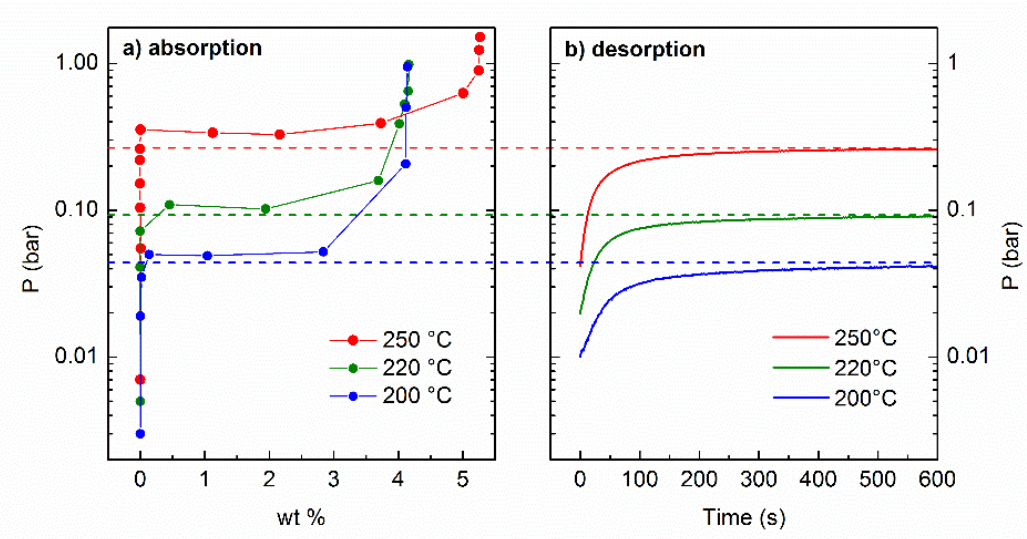

Figure 5: (a) PCl absorption branches and (b) pressure evolution of the first desorption steps reaching equilibrium, at different temperatures, on sample $A$.

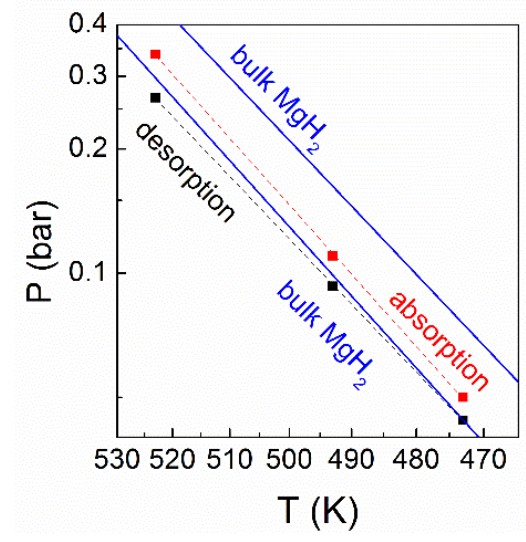

Figure 6: Van 't Hoff plot of the equilibrium points showed in Fig. 5 for sample A. The dashed lines show the best fit to the data. The solid lines are drawn from the values reported in Table 2 for bulk $\mathrm{MgH}_{2}$. 
The reaction kinetics were studied paying attention to avoid strong microstructural and morphological evolution during cycling at different temperatures. To do that, $\mathrm{H}$ desorption-absorption cycles were recorded in two sets of measurements, every time in order of decreasing temperature. In the first set, identified as $\mathrm{T}_{\max }=250{ }^{\circ} \mathrm{C}$, kinetics were measured first at $250^{\circ} \mathrm{C}$ and subsequently at $235{ }^{\circ} \mathrm{C}, 220{ }^{\circ} \mathrm{C}, 205$ ${ }^{\circ} \mathrm{C}$ (Fig. 7a). In the second set, the order was $300{ }^{\circ} \mathrm{C}$, followed by $265{ }^{\circ} \mathrm{C}, 250{ }^{\circ} \mathrm{C}$ and $205{ }^{\circ} \mathrm{C}$ (Fig. $7 \mathrm{~b}$ ) and we will refer to it as $\mathrm{T}_{\max }=300^{\circ} \mathrm{C}$. The initial pressure was chosen in order to maintain the same driving force, namely $\mathrm{T}_{\mathrm{DF}}=\mathrm{T}\left(1-\sqrt{\mathrm{P}_{\mathrm{eq}} / \mathrm{P}_{\mathrm{a}}}\right)=230 \mathrm{~K}$ for absorptions and $\mathrm{T}_{\mathrm{DF}}=\mathrm{T}\left(1-\sqrt{\mathrm{P}_{\text {des }} / \mathrm{P}_{\mathrm{eq}}}\right)=320 \mathrm{~K}$ for desorptions, resulting in an initial pressure between $8 \mathrm{mbar}$ and $320 \mathrm{mbar}$ for desorptions and between 260 mbar and 4.5 bar for absorptions for the $205-300{ }^{\circ} \mathrm{C}$ temperature range. All the curves were fitted with the Johnson-Mehl-Avrami (JMA) model for random nucleation and growth:

$$
\alpha=1-\exp \left(-(\mathrm{kt})^{n}\right)
$$

where $\alpha$ is the reacted fraction at the time $t$. The data fitted were in the $0<\alpha<0.8$ range, as the JMA model hypotheses do not hold in the last stage of the phase transition. The kinetic parameters $k$ derived from the fits at different temperatures are shown in the Kissinger plot in Fig. 8. The activation energy $\mathrm{E}_{\mathrm{A}}$ was calculated for the two sets of measurements separately, according to the Arrhenius law $k=k_{0} \exp \left(-E_{A} / R T\right)$. The values of $\mathrm{E}_{\mathrm{A}}$ are compared in Table 3 to those reported for bulk $\mathrm{MgH}_{2}$ [25] and for $\mathrm{MgH}_{2}$ catalysed with $\mathrm{Nb}_{2} \mathrm{O}_{5}$ [26]. The fitted Avrami parameters $\mathrm{n}$ for the first set of cycles are $n_{\mathrm{abs}}\left(T_{\max }=250^{\circ} \mathrm{C}\right)=(0.9 \pm 0.1)$ for absorptions and $n_{\text {des }}\left(T_{\max }=250^{\circ} \mathrm{C}\right)=(2.0 \pm 0.1)$ for desorptions. For the second set of cycles the Avrami parameters are $n_{\mathrm{abs}}\left(T_{\max }=300^{\circ} \mathrm{C}\right)=(1.0 \pm 0.1)$ and $n_{\mathrm{des}}\left(T_{\max }=300^{\circ} \mathrm{C}\right)=(1.6 \pm 0.3)$.

Table 3: sample A energy of activation for $\mathrm{H}$-absorption and desorption obtained from the linear fits in Fig. 8. $\mathrm{E}_{\mathrm{A}}$ values for bulk $\mathrm{MgH}_{2}$ and $\mathrm{MgH}_{2}+\mathrm{Nb}_{2} \mathrm{O}_{5}$ are reported for comparison.

\begin{tabular}{|c|c|c|c|}
\hline \multicolumn{2}{|c|}{$E_{A}\left(k J \mathrm{~mol}^{-1}\right)$} & Absorption & Desorption \\
\hline \multirow{2}{*}{ Sample A } & After $250^{\circ} \mathrm{C}$ & $155 \pm 11$ & $95 \pm 8$ \\
\hline & After $300^{\circ} \mathrm{C}$ & $68 \pm 8$ & $78 \pm 4$ \\
\hline \multicolumn{2}{|c|}{ Bulk $\mathrm{MgH}_{2}[25]$} & $95 \div 130$ & $120 \div 160$ \\
\hline \multicolumn{2}{|c|}{$\mathrm{MgH}_{2}+\mathrm{Nb}_{2} \mathrm{O}_{5}[26]$} & 61 & - \\
\hline
\end{tabular}
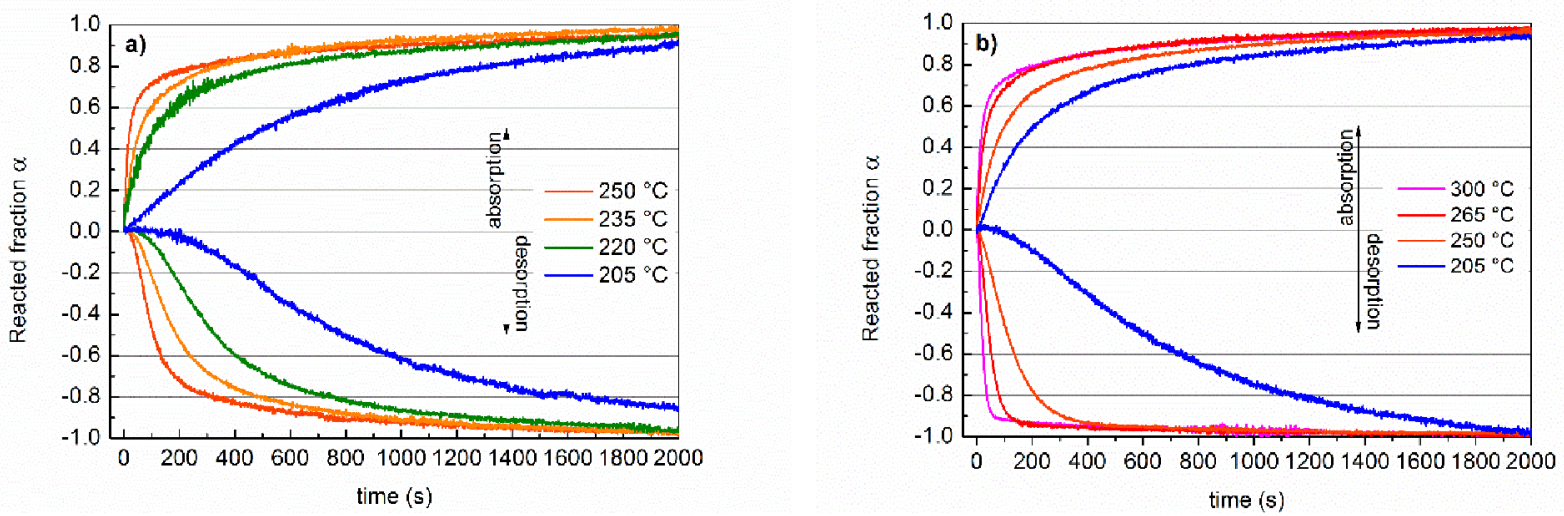

Figure 7: $\mathrm{H}$-sorption kinetics on sample A measured in order of decreasing temperatures starting (a) from $250{ }^{\circ} \mathrm{C}$ and then (b) from 300 ${ }^{\circ} \mathrm{C}$. The reacted fraction is normalised between 0 and -1 for desorption. 
Table 4: weight fraction and mean crystallite size of the compounds detected by PXD in the samples A and B after cycling.

\begin{tabular}{c|cc|cc} 
& \multicolumn{2}{|c|}{ Sample A } & \multicolumn{2}{c}{ Sample B } \\
& Abundance (wt.\%) & Cryst. size (nm) & Abundance (wt.\%) & Cryst. size (nm) \\
\hline $\boldsymbol{\beta}-\mathbf{M g H}_{\mathbf{2}}$ & $74.0 \pm 1.8$ & $134 \pm 2$ & $40.0 \pm 0.6$ & $30 \pm 1$ \\
$\boldsymbol{\gamma}-\mathbf{M g H}_{\mathbf{2}}$ & - & - & - & - \\
$\mathbf{M g O}$ & $12.7 \pm 0.5$ & $5.5 \pm 1.7$ & $24.8 \pm 0.6$ & $6 \pm 1$ \\
$\mathrm{TiH}_{\mathbf{2}}$ & $12.3 \pm 0.6$ & $3 \pm 1$ & $30.2 \pm 0.7$ & $6 \pm 1$ \\
$\mathbf{M g}$ & $1.0 \pm 0.1$ & - & $5.0 \pm 0.2$ & -
\end{tabular}

Fig. 9 compares the $\mathrm{H}$-absorption kinetics of sample $\mathrm{A}$ (low Ti content) and sample B (high Ti content) at $250{ }^{\circ} \mathrm{C}$ and $200^{\circ} \mathrm{C}$.

Finally, the samples were investigated by PXD after the last $\mathrm{H}$-absorption cycle in the Sievert's apparatus. From the patterns in Fig. $2 \mathrm{~b}$ and the refined values in Table 4, it is seen that $\gamma-\mathrm{MgH}_{2}$ disappears upon cycling and grain growth occurs, but the grade of the coarsening is much lower for the sample with higher Ti content.

\section{Discussion}

In situ hydrogenation and low temperature cycling From the PXD patterns in Fig. $2 \mathrm{a}$ it is clear that the metallic Mg-Ti NPs collected after the evaporation were successfully in situ hydrogenated at $150{ }^{\circ} \mathrm{C}$ in less than $3600 \mathrm{~s}$. In a previous work [22], where a detailed structural characterisation of Mg-Ti NPs with and without in situ hydrogenation was carried out, it is shown that a metastable solid solution of $\mathrm{Ti}$ in $\mathrm{Mg}$ forms during the evaporation. In situ hydrogenation leads to irreversible decomposition of the solid solution into $\mathrm{MgH}_{2}$ and $\mathrm{TiH}_{2}$. The presence of $\gamma-\mathrm{MgH}_{2}$ is interesting since its formation is usually

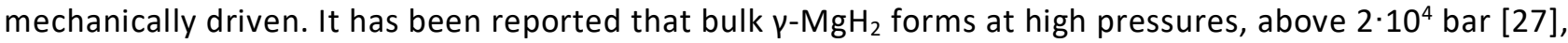
while nanocrystalline $\mathrm{\gamma}-\mathrm{MgH}_{2}$ forms during ball milling [28]. However, it has no $\mathrm{H}$-storage applications since it decomposes upon cycling at higher temperatures (see Fig. 2b). Complete H-absorption at temperatures as low as $150{ }^{\circ} \mathrm{C}$ in less than $3600 \mathrm{~s}$ was possible not only because of the enhanced kinetic properties due to the presence of the Ti-catalyst and of the nanostructure, but also thanks to the highly clean atmosphere of the synthesis chamber that leaves the $\mathrm{Mg}$ surface free from contaminants, mainly $\mathrm{O}_{2}$. Oxide formation not only reduces the total capacity of the material but also affects kinetic properties like $\mathrm{H}$-sorption speed and activation energy. Therefore, particular attention to the experimental synthesis
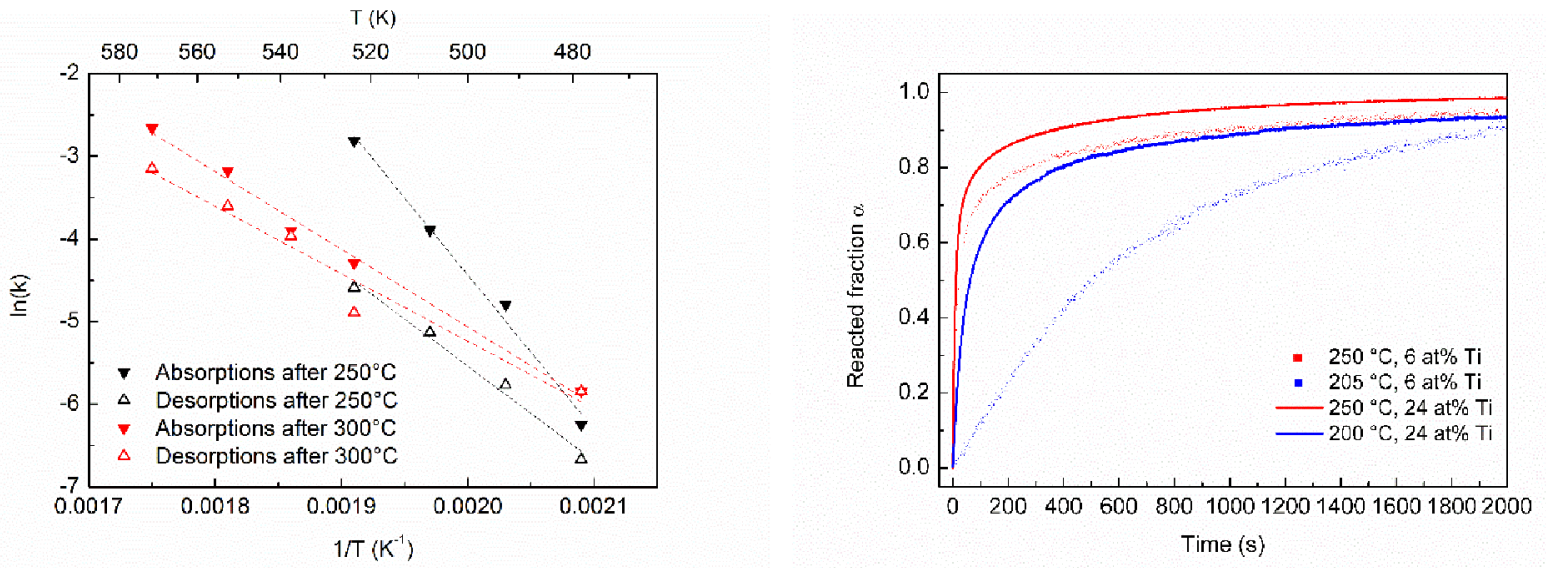

Figure 8: Kissinger plot for the kinetics in Fig. 7 after $T_{\max }=250^{\circ} \mathrm{C}$ in black, after $\mathrm{T}_{\max }=300{ }^{\circ} \mathrm{C}$ in red, on sample $\mathrm{A}$.

Figure 9: comparison of the reaction kinetics at $250^{\circ} \mathrm{C}$ and $\sim 200^{\circ} \mathrm{C}$ of sample $A$ after $T_{\max }=250^{\circ} \mathrm{C}$ and sample $B$. 
conditions must be paid when trying to determine the intrinsic properties of the system.

Sample A performed a complete cycle in $\sim 2000 \mathrm{~s}$ at $205^{\circ} \mathrm{C}$ and pressures $p_{\text {des }}=8 \mathrm{mbar}$ for desorption, $p_{\text {abs }}$ = 260 mbar for absorption (Fig. 7). This is a remarkable result for a Mg-based system, especially because $\mathrm{H}$-desorption at these temperatures are rarely reported [29].

Reaction mechanism The SR-PXD measurements (Fig. 3) show the development of the H-sorption reactions. The only observed Bragg reflections are $\mathrm{Mg}$ and $\mathrm{MgH}_{2}$, and $\mathrm{TiH}_{2}$ presence is evinced from Fig. $2 \mathrm{~b}$, i.e. Ti-Mg based alloy formation is not observed. Fig. 4 shows that the intensities of $\mathrm{Mg}$ and $\mathrm{MgH}_{2}$, separately normalised between 0 and 1 , always sum to 1 point by point, demonstrating that the ongoing reaction is simply the reversible hydrogen absorption and desorption of magnesium. The equilibrium measurements in the Sievert apparatus (Table 2) also support this result. In fact, Sample A exhibits the same enthalpy and entropy of hydride formation as bulk $\mathrm{MgH}_{2}$, even though the equilibrium points of the Van 't Hoff plot (Fig. 6) are between $200^{\circ} \mathrm{C}$ and $250{ }^{\circ} \mathrm{C}$, a temperature range where $\mathrm{H}$-sorption in bulk $\mathrm{MgH}_{2}$ has not been reported because of the sluggish kinetics. Therefore, the observation of a full desorption-absorption cycle at $205{ }^{\circ} \mathrm{C}$ (Fig. 7) does not originate from a new reaction path or a change in the thermodynamics, but is ascribed only to an improvement of the kinetics thanks to the nanostructure and the catalytic effects of $\mathrm{TiH}_{2}[10,11]$.

Ti addition The presence of Ti atoms prevents NPs coalescence, a phenomenon that occurs extensively during IGC synthesis of pure $\mathrm{Mg}$ [30]. As Table 1 shows, the crystallite size of $\beta-\mathrm{MgH}_{2}$, representative of the mean NP size, is smaller for the sample with higher Ti content. Grain growth during cycling is also reduced with increasing $\mathrm{Ti}$ concentration (see Table 4). The comparison between the absorption kinetics of the two samples (Fig. 9) shows that the already fast kinetics observed for sample A can be further improved increasing catalyst concentration, obviously at the cost of a reduced capacity of the material. As mentioned before, a higher Ti content reduces the NPs size, which is also beneficial for the reaction speed.

Thermally induced changes The differences in the $\mathrm{H}$-sorption kinetics induced after cycling sample $\mathrm{A}$ at $\mathrm{T}_{\max }=250^{\circ} \mathrm{C}$ and after $\mathrm{T}_{\max }=300^{\circ} \mathrm{C}$ are summarised in the Kissinger plot in Fig. 8. The two sets of measurements (red and black data in Fig. 8) have very different slopes, reflecting different activation energies. After $\mathrm{T}_{\max }=250^{\circ} \mathrm{C}, \mathrm{E}_{\mathrm{A}}$ values are in the range usually reported for bulk $\mathrm{MgH}_{2}$ [25] for both absorptions and desorptions, but after $\mathrm{T}_{\max }=300{ }^{\circ} \mathrm{C}, \mathrm{E}_{\mathrm{A}}$ greatly decreases, reaching $68 \mathrm{~kJ} \mathrm{~mol}^{-1}$ for absorption and $78 \mathrm{~kJ} \mathrm{~mol}^{-1}$ for desorption (Table 3). These values of $\mathrm{E}_{\mathrm{A}}$ compete with the ones found using $\mathrm{Nb}_{2} \mathrm{O}_{5}$, one of the best catalyst for $\mathrm{H}$-sorption reactions in $\mathrm{Mg}$ known so far [26]. We suggest that the decrease of $\mathrm{E}_{\mathrm{A}}$ after cycling at $300^{\circ} \mathrm{C}$ is connected to surface activation, which may result from the breaking of the $\mathrm{MgO} /$ $\mathrm{Mg}(\mathrm{OH})_{2}$ layers at the NPs surface. The decrease of the rate constant $k$, observed for $\mathrm{H}$-absorption despite the decreased activation energy, may be due to NPs coarsening and grain growth after cycling at $300^{\circ} \mathrm{C}$.

The Avrami parameters $n$ convey some information on kinetics and geometry of the reaction mechanisms. We recall that $\mathrm{n}=\mathrm{a}+\mathrm{bc}$, where $a$ is related to the nucleation rate and equals 0 when nucleation is instantaneous and 1 when it is constant, $b$ is the dimensionality $D$ of the growth and $c$ equals 0.5 or 1 when the growth is diffusion or interface controlled, respectively. The rate limiting step is generally considered to be the slow motion of $\mathrm{H}$ atoms in $\mathrm{MgH}_{2}$, meaning that absortions are diffusion controlled $(c=0.5)$ while desorptions are interface controlled $(c=1)$. Since all absorptions have $\mathrm{n}_{\mathrm{abs}} \sim 1$, the mechanism could be instantaneous nucleation with 2-D diffusion controlled growth $(a=0, b c=1)$ or decreasing nucleation rate with 1-D diffusion controlled growth $(a \sim 0.5, b c=0.5)$. For desorptions, $n_{\mathrm{des}}\left(T_{\max }=250^{\circ} \mathrm{C}\right)=(2.0 \pm 0.1)$ and $n_{\mathrm{des}}\left(T_{\max }=300^{\circ} \mathrm{C}\right)=(1.6 \pm 0.3)$. As mentioned before, 
desorptions are interface controlled, therefore, assuming $c=1, n_{\text {des }}$ values are compatible with instant nucleation and $\sim 2-D$ motion of the interfaces $(a=0, b \sim 2)$ or nearly constant nucleation and 1-D interface motion $(a \sim 1, b=1)$.

The relatively light weight of $\mathrm{TiH}_{2}$ as a catalyst allows to reach high gravimetric capacities. The capacity measured during the PCls of sample B was $4.1 \mathrm{wt} \%$ at low temperatures (Fig. 5a) and increases to 5.3 wt\% when heated up to $250{ }^{\circ} \mathrm{C}$. The increased capacity might be due to activation effects in a portion of the sample, since the $\mathrm{PCl}$ at $250^{\circ} \mathrm{C}$ was chronologically the last one. The theoretical reversible hydrogen capacity $\mathrm{C}_{\mathrm{x}}$ of a $\mathrm{MgH}_{2}-\mathrm{TiH}_{2}$ composite with $\mathrm{x}$ at\% $\mathrm{Ti}$ is calculated by the formula

$$
\mathrm{C}_{\mathrm{x}}=\mathrm{C}_{0} \frac{(100-\mathrm{x}) \mathrm{M}_{\mathrm{MgH} 2}}{(100-\mathrm{x}) \mathrm{M}_{\mathrm{MgH} 2}+\mathrm{x} \mathrm{M}_{\mathrm{TiH} 2}}
$$

where $\mathrm{C}_{0}=7.66 \mathrm{wt} \%$ is the theoretical capacity of $\mathrm{MgH}_{2}, \mathrm{M}_{\mathrm{MgH} 2}=26.32 \mathrm{~g} \mathrm{~mol}^{-1}$ and $\mathrm{M}_{\mathrm{TiH} 2}=49.88 \mathrm{~g}$ $\mathrm{mol}^{-1}$ are the molar masses of the hydrides. For sample $\mathrm{A}(\sim 6$ at\% $\mathrm{Ti})$, the theoretical maximum is $\mathrm{C}_{6}=$ $6.83 \mathrm{wt} \%$, which is higher than the measured value $(5.3 \mathrm{wt} \%)$. We attribute this difference mainly to oxide formation (Table 4) that could be reduced by improving sample transfer and increasing the amount of synthesised material.

\section{Conclusions}

Bottom-up synthesised Mg-Ti NPs via Inert Gas Condensation (IGC) were in situ hydrogenated at $150{ }^{\circ} \mathrm{C}$, resulting in the formation of a $\mathrm{MgH}_{2}-\mathrm{TiH}_{2}$ nanocomposite. In situ SR-PXD and equilibrium measurements between $200{ }^{\circ} \mathrm{C}$ and $280^{\circ} \mathrm{C}$ revealed that the ongoing reaction during $\mathrm{H}$-sorption is the transition between the metallic and the hydride phase of $\mathrm{Mg}$, with the same thermodynamic properties of bulk $\mathrm{Mg}$. Hence, neither the particle sizes of $>10 \mathrm{~nm}$ nor the addition of $\mathrm{TiH}_{2}$ give rise to changed thermodynamics. However, Ti addition ( 6 at\%) is sufficient to greatly enhance the $\mathrm{H}$-sorption kinetics, while keeping a high storage capacity, up to $5.3 \mathrm{wt} \%$. The combination of the nanostructure of $\mathrm{Mg}$ and the presence of $\mathrm{TiH}_{2}$ allowed to cycle the samples in $\sim 2000 \mathrm{~s}$ at $200^{\circ} \mathrm{C}$ with $p_{\text {des }}=8 \mathrm{mbar}$ and $p_{\text {abs }}=260 \mathrm{mbar}$. On cycling at higher temperatures $\left(300^{\circ} \mathrm{C}\right)$ the activation energy for both absorption $\left(68 \mathrm{~kJ} \mathrm{~mol}^{-1}\right)$ and desorption $\left(78 \mathrm{~kJ} \mathrm{~mol}^{-1}\right)$ is reduced owing to surface activation effects. Increasing Ti content ( 24 at\%) still yields a $\mathrm{MgH}_{2}-\mathrm{TiH}_{2}$ nanocomposite with reduced grain growth during synthesis and cycling and slightly improved reaction speed, but at the cost of a reduced capacity.

\section{Acknowledgements}

The assistance of F. Corticelli and V. Morandi (IMM-CNR, Bologna) during FE-SEM observations is gratefully acknowledged.

Part of this work was supported by the COST Action MP1103 "Nanostructured materials for solidstate hydrogen storage". We are grateful to the beamline 1711 at MAXlab, Lund, Sweden for the provision of beamtime.

\section{References}

1. L. H. Jepsen, M. B. Ley, Y.-S. Lee, Y. W. Cho, M. Dornheim, J. O. Jensen, Y. Filinchuk, J. E. Jørgensen, F. Besenbacher and T. R. Jensen, Materials Today, 2014, 17, p.129.

2. M. B. Ley, L. H. Jepsen, Y.-S. Lee, Y. W. Cho, J. M. Bellosta von Colbe, M. Dornheim, M. Rokni, J. O. Jensen, M. Sloth, Y. Filinchuk, et al., Materials Today, 2014, 17, p.122.

3. G. Liang, J. Alloys Compd., 2004, 370, p.123 
4. T. K. Nielsen, K. Manickam, M. Hirscher, F. Besenbacher and T. R. Jensen, ACS Nano, 2009, 3, p.3521.

5. G. Liang, J. Huot, S. Boily, A. Van Neste and R. Schulz, J. Alloys Compd., 1999, 292, p.247

6. W. Oelerich, T. Klassen and R. Bormann, J. Alloys Compd., 2001, 315, p.237.

7. L. P. A. Mooij, A. Baldi, C. Boelsma, K. Shen, M. Wagemaker, Y. Pivak, H. Schreuders, R. Griessen and B. Dam, Adv. Energy Mater., 2011, 1, p.754

8. A. Baldi, M. Gonzalez-Silveira, V. Palmisano, B. Dam and R. Griessen, Phys. Rev. Lett., 2009, 102, p.226102

9. L. Pasquini, M. Sacchi, M. Brighi, C. Boelsma, S. Bals, T. Perkisas and B. Dam, Int. J. Hydrogen Energy, 2014, 39, p.2115

10. J. Lu, Y. J. Choi, Z. Z. Fang, H. Y. Sohn and E. Rönnebro, J. Am. Chem. Soc., 2009, 131, 15843

11. F. Cuevas, D. Korablov and M. Latroche, Phys. Chem. Chem. Phys., 2012, 14, p.1200

12. Jensen, I. J. T.; Diplas, S.; Løvvik, O. M. Phys. Rev. B 2010, 82, p.174121

13. A. Anastasopol, T. V. Pfeiffer, J. Middelkoop, U. Lafont, R. J. Canales-Perez, A. Schmidt-Ott, F. M. Mulder and S. W. H. Eijt, J. Am. Chem. Soc., 2013, 135, p.7831

14. K. Asano, H. Enoki and E. Akiba, J. Alloys Compd., 2009, 478, p.117

15. K. Asano, H. Enoki and E. Akiba, J. Alloys Compd., 2009, 480, p.558

16. G. Liang and R. Schulz, J. Mater. Sci., 2003, 38, p.1179

17. P. Vermeulen, R. A. H. Niessen and P. H. L. Notten, Electrochem. Commun., 2006, 8, p.27

18. D. M. Borsa, R. Gremaud, A. Baldi, H. Schreuders, J. H. Rector, B. Kooi, P. Vermeulen, P. H. L. Notten, B. Dam and R. Griessen, Phys. Rev. B: Condens. Matter Mater. Phys., 2007, 75, p. 205408

19. L. Lutterotti, M. Bortolotti, G. Ischia, I. Lonardelli and H.R. Wenk, Zeitschrift für Kristallographie Supplements, 2007, 26, p.125

20. B. R. S. Hansen, K. T. Møller, M. Paskevicius, A.-C. Dippel, P. Walter, C. J. Webb, C. Pistidda, N. Bergemann, M. Dornheim, T. Klassen, T. et al., J. Appl. Cryst., 2015, 48, p.1234.

21. D. Korablov, F. Besenbacher, T. R. Jensen, International Journal of Hydrogen Energy, 2014, 39, p.9700, http://dx.doi.org/10.1016/j.ijhydene.2014.03.141

22. M. Calizzi, F. Venturi, M. Ponthieu, F. Cuevas, V. Morandi, T. Perkisas, S. Bals and L. Pasquini, Physical Chemistry Chemical Physics, 2016, 18, p. 141, DOI: 10.1039/C5CP03092G

23. R. Wiswall, Hydrogen in Metals II - Chapter 5, p.209, Spriner-Verlag, 1978, http://dx.doi.org/.1007/3-540-08883-0

24. H. Shao, M. Felderhoff, F. Schüth, International Journal of Hydrogen Energy, 2011, 36, p.10828, http://dx.doi.org/10.1016/j.ijhydene.2011.05.180

25. J.F. Fernández, C.R. Sánchez, Journal of Alloys and Compounds, 2002, 340, p.189, http://dx.doi.org/10.1016/S0925-8388(02)00120-2

26. G. Barkhordarian, T. Klassen, R. Bormann, Journal of Alloys and Compounds, 2004, 364, p.242, http://dx.doi.org/10.1016/S0925-8388(03)00530-9

27. M. Bortz, B. Bertheville, G. Böttger, K. Yvon, Journal of Alloys and Compounds, 1999, 287, p.L4, http://dx.doi.org/10.1016/S0925-8388(99)00028-6

28. J. Huot, G. Liang, S. Boily, A. Van Neste, R. Schulz, Journal of Alloys and Compounds, 1999, 293295, p.495-500, http://dx.doi.org/10.1016/S0925-8388(99)00474-0

29. K.-J. Jeon, H. R. Moon, A. M. Ruminski, B. Jiang, C. Kisielowski, R. Bardhan and J. J. Urban, Nature Materials 2011, 10, 286-290, doi:10.1038/nmat2978

30. F. Venturi, M. Calizzi, S. Bals, T. Perkisas and L. Pasquini, Mater. Res. Express, 2015, 2, p.015007 doi:10.1088/2053-1591/2/1/015007 